\title{
Constructing the Landscape of Consciousness in News Stories ${ }^{1}$
}

\author{
José Sanders and Hans Hoeken
}

\section{Introduction: The Social-cognitive and Persuasive Functions of Narratives}

In every known culture, people tell each other narratives. ${ }^{2}$ Toolan (2001) defines a narrative as "a perceived sequence of non-randomly connected events, typically involving sentient beings as the experiencing agonist from whose experience we can learn."3 The use of "learn" suggests that narratives may serve an adaptive function. It has been argued that this function lies in narratives' contribution to the smooth collaboration between individuals within a group. ${ }^{4}$ Since collaborating individuals were more successful in gathering food and fighting enemies than individuals fending for themselves, their chances of survival increased.

Successful collaboration requires the capacity to decide who can be trusted to do their share and the capacity to turn the unwilling ones around. These capacities are referred to as social intelligence, i.e., the ability to understand, predict, and manipulate the behaviour of other people. ${ }^{5}$ The first of these capacities, understanding a person's behaviour, requires insight into the goals and beliefs of this person, for, as Tomasello et al. (2005) observe, "the same physical movement may be seen as giving an object, sharing it, loaning it, moving it, getting rid of it, returning it, trading it, selling it, and so on - depending on the goals and the intentions of the actor." ${ }^{6}$ To be able to accurately interpret this action, one has to master "mind reading": inferring the goal and thoughts guiding these actions. Mind reading is also essential for the ability to predict a person's behaviour. Knowledge about a person's goals and his or her

1 The authors wish to thank an anonymous reviewer of this paper for his valuable comments.

2 Brown (1991).

3 Toolan (2001) 8.

4 Boyd (2009); Scalisa Sugiyama (1996); Tomasello (2008).

5 Humphrey (1976).

6 Tomasello et al. (2005) 675 .

(C) JOSÉ SANDERS AND HANS HOEKEN, 2015 | DOI 10.1163/9789004270848_009

This is an open access chapter distributed under the terms of the Creative Commons AttributionNoncommercial 3.o Unported (CC-BY-NC 3.0) License. 
beliefs about the barriers and opportunities connected to those goals, enable one to predict this person's next move. Finally, to manipulate people's behaviour, one has to point out that the preferred behaviour will have more favourable consequences compared to its alternatives. Social intelligence therefore requires relevant information on how a person's goals and beliefs guide his or her actions as well as information on what the consequences of these actions will be.

Boyd (2009) argues that narratives provide the training material for developing social intelligence. Narratives are the perfect vehicle to learn about the way in which people's goals and beliefs guide their actions and subsequently to document the actions' consequences while attracting and keeping their audience's interest because of the entertainment they provide. He draws an analogy between people's seemingly insatiable thirst for stories and the function of play. For instance, lion cubs mock-fight with each other; this play is entertaining but it also leads to the development of skills that are important for survival in their adult life as they are essential for killing their prey. According to Boyd, stories have similar characteristics: they provide entertainment but also train humans in the crucial art of understanding, predicting, and manipulating other people's behaviour.

Pinker (1997) claims that stories enable the audience to explore the consequences of actions by observing how fictitious characters in hypothetical situations act and what the consequences of these acts are. In his words, fiction "is especially compelling when the obstacles to the protagonist's goals are other people in pursuit of incompatible goals."(...) "The intrigues of people in conflict can multiply out in so many ways that no one could possibly play out the consequences of all courses of action in the mind's eye. Fictional narratives supply us with a mental catalogue of the fatal conundrums we might face someday and the outcomes of strategies we could deploy in them." People may benefit from attending to narratives by (learning to) understand and predict people's behaviour or to chart the consequences of certain actions. However, they do not read a story in order to be manipulated. Story tellers, on the other hand, may strategically focus on some consequences of an action while keeping silent on others in order to increase the favourability of a behavioural alternative.

We can therefore distinguish between a social cognition function and a persuasive function of narratives. This does not imply that there is sharp distinction between "social cognitive narratives" and "persuasive narratives." Exactly the same story can serve both functions; the autobiography (life story) of a person who runs for office can serve as input for the audience to predict how 
this person will act if elected whereas the politician may employ this story to paint a favourable picture of him or herself in order to manipulate the audience's voting behaviour.

Still, some narratives may be more suitable for gaining an understanding of a person's actions whereas others would prove better at illuminating the consequences of certain actions. This difference in suitability appears to be related to Bruner's (1986) distinction between the two landscapes that a narrative constructs: the landscape of action and the landscape of consciousness. Although each narrative constructs both landscapes, narratives can differ with respect to their emphasis on either the characters' actions or on the beliefs and goals guiding these actions. ${ }^{8}$ In an action movie, relatively more attention is paid to the main character's ability, for instance, to perform martial arts while we learn little about the character's history, opinions, and values. In a psychological study, it is the other way around; we do learn a lot about the character's background and thoughts, but little else happens.

The landscape of consciousness appears especially important when trying to understand seemingly erratic behaviour. For instance, Mark Haddon's novel The curious incident of the dog in the night time is very popular among school teachers, not only for its (literary) entertainment value, but also because it (supposedly) provides a view of the landscape of consciousness of an autistic boy. ${ }^{9}$ This view enables teachers to better understand the behaviour of pupils with autism. Similarly, in Dutch health care education, students are required to the read the Dutch novel Hersenschimmen ("Chimeras") by the author Bernlef, a novel depicting the thoughts and experiences of a man suffering from Alzheimer's disease. ${ }^{10}$ It is expected that this novel provides health care workers with a better understanding of the seemingly erratic actions of such patients. Generally, literary texts are being used in medical settings to increase understanding in both care givers and patients. ${ }^{11}$ Pinker's (1997) description of the functions narratives may serve appears to be more related to the landscape of action, as he points to the information about the consequences actions may have. By and large, a narrative in which the landscape of action is emphasized appears to feed into the manipulation dimension of social intelligence, whereas a narrative emphasizing the landscape of consciousness serves the understanding and predicting dimensions. In the next section, we will focus on journalistic background stories and the function they may serve.

\footnotetext{
$8 \quad$ Cupchik and Laszlo (1994).

9 Haddon, M. (2007). The Curious Incident of the Dog in the Night-time. National Geographic Books.

10 Bernlef, J. (1994). Hersenschimmen [Chimeras]. Amsterdam: Querido.

11 Kaptein et al., 2011
} 


\section{Understanding Behaviour and the Landscape of Consciousness}

Boyd (2009) makes a case for the adaptive function of fictional narratives. In his line of argument, he refers to the work by Dunbar $(1996,1998)$ who argues that "the principle function of language was (and still is!) to enable the exchange of social information."12 An important topic for this exchange is the extent to which people do or do not breach (cultural) group norms. Dunbar (2004) argues that such information is important to ensure that every member of his group does his or her fair share of work which is essential for the smooth collaboration within the group and further suggests that commenting on the breach of social norms has a strong impact on people's willingness to "toe the line." ${ }^{.13}$

Nowadays, journalists play an important role in the exchange of social information. Journalists and their news sources both function within an "interpretative community, a cultural site where meanings are constructed, shared, and reconstructed by members of social groups in the course of everyday life."14 For an event to attract a journalist's attention, it has to be newsworthy within the interpretative community. One of the ways in which this criterion can be met is by violating shared expectations. If a person's action sharply deviates from the expected cultural convention, this action becomes newsworthy. For instance, if someone becomes violent without an apparent reason, if a mother kills her children, or if a politician "goes public" on what are considered confidential negotiations, it will make the front page. When society's core values are under threat - such as with physical or political violence or terrorist attacks journalists switch to a cultural narrative that moves the public mind back toward the dominant cultural order. In the case of news that is culturally remote - in the sense that it violates culturally shared norms - narratives must be relied upon more heavily to assist journalists' sense-making, and the news is more mythically-laden. ${ }^{15}$ The reason being that such remote acts automatically evoke the question of why actors acted in the way they did.

This "why" question is related to the observation by Tomasello et al. (2005) cited above: We need to know what the intention of the person was when performing the action, that is, we need such information to understand why soccer hooligans act violently in and outside of the stadium, why suicide bombers would sacrifice their lives to kill others, why a mother would suffocate her new born babies. Thus, news journalism plays out myths, rituals, and archetypes, in

\footnotetext{
12 Dunbar (1998) 98.

13 Dunbar (2004) 108.

14 Berkowitz and TerKeurst (1999) 125.

15 Nossek and Berkowitz (2006) 691.
} 
order to "get the story," for "all that audiences [try] to do is find reassurance and meaning in a rather chaotic news situation."16 By drawing on these anthropological insights, textual analysis may reveal this narrative role of media. ${ }^{17}$ Modern nonfiction narratives may be revelations of important cultural standards and beliefs. ${ }^{18}$ These stories are made credible, logically motivated, and morally acceptable by applying techniques that are not so much typically literary, but can be traced back to the structure of Greek mythology and drama, such as altered chronology, discovery, peripety (or complication), and resolution. ${ }^{19}$

Our aim is to explore further why and how news narratives of the culturally remote are being told. According to Bruner (1990), acts that deviate from our culturally based expectations require a story whose function is "to find an intentional state that mitigates or at least makes comprehensible a deviation from a canonical cultural pattern." ${ }^{20}$ More specifically, such acts require a reconstruction of the landscape of consciousness leading up to the action. Next to "hard news" descriptions of the events, newspapers run background stories in which they aim to provide such a reconstruction. Although relating the same events, these news stories differ strongly from each other with respect to the story telling techniques employed. We will argue that the main difference between hard news items and background stories of the same event resides in the extent to which the journalists try to sketch the goals, beliefs, and intentions of the characters, using such narrative techniques as altered chronology, discovery, complication, and resolution. These narrative techniques allow for journalists to intertwine their own point of view with their source's points of view. Analyzing two news articles reporting on the same event with tools and models developed in literary stylistics and cognitive linguistics, we aim to show how the strategic use of language by the journalists opens up different perspectives on the event. These choices are not so much the result of the need to please the readers but rather as a necessary means to gain the readers' understanding for seemingly erratic behaviour. In the following section, we will elaborate this claim, and we will argue that Mental Space Theory helps to describe the news sources' landscape of consciousness.

\footnotetext{
16 Fürsich (2009) 245.

17 Ibidem.

$18 \quad$ Marsh (2010) 295 .

$19 \operatorname{Marsh}(2010) 296$.

$20 \quad$ Bruner $(1990) 50$.
} 


\section{Representing the Landscape of Consciousness in a Mental Space Model}

In this section, a short "hard" news text and a longer "soft" news article are analyzed and compared. ${ }^{21}$ Both texts were taken from Dutch newspaper De Volkskrant and describe the onset of events that lead to a much discussed case: the "Beverwijkse Baby Murders" (December 2005 - Fall 2006). This case prompted articles to be written in various journalistic news genres, among which were news reports covering one subject and reportages reconstructing news facts or events. When we compare one such short news report with a longer background story, differences in register become evident.

Constructing a landscape of consciousness implies that the reader is able to reconstruct what a particular character thought, believed, felt and wanted; in other words: a reconstruction of this person's perspective on the situation and events constituting the news facts. Fauconnier's Mental Space Theory ${ }^{22}$ offers a framework to describe such a reconstruction. In each communicative situation, a basic space can be assumed as a vantage point in which time, space, reference point and truth are linked to the primary speaker/narrator, ${ }^{23}$ in this case the journalist. The basic space is illustrated in the first, short news report. ${ }^{24}$

1. BEVERWIJK - 1. The police are investigating the death of a newborn infant in Beverwijk. 2. The body was discovered Wednesday in a house in Haarlem. 3. Because the infant may have been born in a house in Beverwijk, the police are investigating a house there as well. 4 . The mother and her boyfriend have been taken into custody for questioning. (ANP)

From his basic space here-and-now, the journalist describes the order of the events as they are known to him at the time of writing. That is, he describes the investigation as ongoing and positions the discovery of the body in time

21 Because of the illustrative purposes of our analysis in this paper, we have employed mental space theory in a rather loose, non-technical way. A more technical treatment of parts of these texts can be found in Sanders (2010) in which she shows how embedded spaces are created by the use of verbs referring to cognitive activities (e.g., thinking, believing), changes in verb tense, and referential choices.

22 Fauconnier (1985) [1994]; Sweetser and Fauconnier (1996).

23 Sanders, Sanders and Sweetser (2009, 2012).

24 Dutch national newspaper De Volkskrant, December 28, 2005; translated and quotation labels added. http://www.volkskrant.nl/archief_gratis/article1014895.ece/Politie_onderzoekt_dood_van_pasgeboren_baby. Retrieved on December 3, 2009, 2.30 PM. 
("Wednesday"). The presumed news source - the police - must have related the events, but their utterances and perceptions are represented in a distanced way only. They have no voice, nor are their thoughts represented. ${ }^{25}$ The report represents the journalist's landscape of consciousness, and only his, with respect to this news event. Note that in this hard news event, the chronology is iconic; "discovery," "complication," and "resolution" are not elaborated.

Within the basic space, one can open up so-called embedded spaces which can be filled with information that is attributable to another person, information on what that person thought, felt, and believed at a certain point in time. ${ }^{26}$ These embedded spaces enable the representation of other people's landscapes of consciousness at other points in the narrative chronology. This mechanism can be seen in example $2,{ }^{27}$ which presents the first part of a long background news story ( 1.700 words) published at a later date during the trial. In the lead-in (o), the first space in this background article is the journalist's. In this base space, the dead child is referred to as "a fourth corpse," since it was found first, but born last and reported last from the journalist's starting point. From this base space, a further embedded space (1) is created by the verb sees. This verb of cognition functions as a space builder and connects the new embedded space to the first narrative character who performs the act of seeing: Carla. In this second embedded space, the discovery of the baby is retold more elaborately, from her perspective and from an earlier point in time.

2. O. On December 22, 2005, the criminal investigation department discovered, in a waste bin in the garden of Jeroen and Etta in Beverwijk, three buckets that each contained the small body of an infant. A fourth corpse had been found the day before. Last Monday, the mother appeared in court, today the father. By (name journalist).

1. Shortly before Christmas 2005 Carla, who has just become a grandmother to little Esra, is rummaging around in the cellar of her Haarlem residence. She sees a green backpack that she does not know. That will be Etta's, she thinks. Etta is her eldest daughter, who recently moved back in with her. (...) When replacing the backpack Carla gets the impression

25 Only the verb discovered implicitly demarcates cognitive activity by the non-specified actor, indicating the mere presence of a consciousness (Sanders and Redeker 1993: implicit viewpoint).

$26 \quad$ Sanders and Redeker (1996).

27 Weert Schenk, Volkskrant, October 6, 2006 "Alles zou goed komen" [Everything was going to be all right]; translated and quotation labels added. http://www.volkskrant.nl/archief_ gratis/article577454.ece/Alles_zou_goed_komen. Retrieved on December 3, 2009, 2.30 PM. 
that it contains wet clothes. She takes out a garbage bag, which contains more garbage bags and towels, and moments later she is holding (lit. "stands in her hands with") a dead infant, wrapped in a red T-shirt (...). An unbearable smell fills the cellar.

2. The family doctor, who at Carla's request arrives within moments, sees a full-term infant, a girl well over seven pounds. Later it is determined that the child has died weeks before, but that it was not still-born.

3. Carla thinks that Etta is the mother. Whose baby could it be otherwise? (lit. Of who else should the baby be?) She asks a friend and a sisterin-law to come to her house. Only then does she phone her daughter. Etta is riding her bike to school to pick up the children she looks after.

4. "Please come at once," she hears her mother say, "I have found something." Etta starts to cry. At her mother's home, Etta at first does not want to enter. She is very upset. She does not want to talk about anything, she wants to die.

5. Later that day she relates that the baby is hers. It was born in Beverwijk, in the house where she lived with her boyfriend Jeroen who is four years her senior. The exact day of the birth Etta can't remember. It must have been three of four weeks ago, definitely before the delivery of her sister Daphne. (...)

6. Yet, she would ride her bike from Haarlem to her old home in Beverwijk to be with her babies. She would, just like when she still lived there, take the garbage bags out of the bin and fantasize about how things could have been different. After the separation from Jeroen she had decided to take the last baby with her to Haarlem: then she would not be so lonely. (...)

7. She was afraid that Jeroen would be angry if he heard that she was pregnant. She told nobody that she was pregnant. She did not go to see a doctor about it. Etta does not understand how her boyfriend never noticed that she was pregnant. She had a big belly and her breasts had grown. Prosecution also thinks this is unimaginable. (...)

8. At each birth she hoped that Jeroen would enter the bathroom and save the baby. She never thought that she would actually kill the children. Yet that is what happened. But she could not part from her lifeless children. That is why she put them in the garbage bin.

9. According to Jeroen the children would have been welcome. He blames himself for not truly having known Etta. Etta and Jeroen have decided to have their four babies cremated as soon as possible. The ashes will be in one urn. (End of news story). 
In the second sentence of fragment 1 , several cognitive verbs indicate Carla news source's mental activity. "She sees a green backpack that she does not know." Here, these signals open an embedded space which is subsequently filled with perceptions and thoughts that are connected to this source and of which the validity is restricted to this source there and then. "That will be Etta's, she thinks." The thoughts may even turn out later to be false. "When replacing the backpack Carla gets the impression that it contains wet clothes." In addition, discoveries and perceptions are represented that are particular for this character at the narrated moment. "She takes out a garbage bag, which contains more garbage bags, towels and moments later she is holding a dead infant, wrapped in a red T-shirt. An unbearable smell fills the cellar." In particular, the perception in the last sentence "unbearable smell" colours the narrator's text as represented from the character's perspective: it is she who smells.

The representation from this person's perspective also explains why the child she discovers is referred to as new, "a dead infant." While the reader already knows about the dead children as they have been introduced in the article's introduction, it was new to this person at that period of time. Sanders and Redeker (1993) show how the use of such "late indefinite references" can be explained by the embedded space which represents content valid for the narrative source only. ${ }^{28}$ The referential choice reinforces the discovery which is the dramatic climax of the story as well as the onset to the subsequent complication. In the third paragraph again the use of a cognitive verb, thinks functions as a space builder; subsequently, Carla's embedded mental space is filled with her thoughts in free indirect representation mode. ${ }^{29}$ "Carla thinks that Etta is the mother. Who else could the baby belong to?" Obviously, journalists cannot read their sources' thoughts; they reconstruct them. Such constructed thought elements give a "fictionalized" flavour to the text. In the present example of a background story, this type of fictionalized source representation is pragmatically possible, but it explains why this form will be an exception in "hard" news reports such as example $1 .^{30}$

In addition to the altered chronology, the change of verb tense helps to build the embedded space. After the short lead in the simple past tense, the article

28 A similar case of late indefinite reference is seen in section 2, where the doctor "sees a full-term infant, a girl well over seven pounds": again, for this person, the referent was new.

29 Fludernik (1993); Semino and Short (2004).

30 Reconstructed free indirect thoughts form an attractive means to increase suspense but, when applied in hard news texts, readers tend to find the text less appropriate as a news report (see effect study by Sanders and Redeker, 1993). 
changes to the present tense, which enhances the feeling of immediacy in the narrative text: it advances the subsequent scenes as though in a movie, shot from the point of view of Carla. Notably, the intended effect of representing a horrible discovery as an act of the present, viewed from the perspective of the one making that discovery, is akin to "dramatization": what happened will be more (?) imaginable and literally perceivable. By representing Carla's embedded mental space in the present tense, the journalist facilitates identification with this source who is as ignorant and shocked by the events as anyone else, including the reader, would be. In other words, in order to help readers cross the bridge between lack of understanding and the ability to understand the unintelligible, the journalist starts his story from the perspective of a close relative who is, as the readers are, still unaware of what has happened and why.

Gradually, in the fourth paragraph, the perspective shifts towards the main news character, i.e. the dead baby's mother: Etta. Again, a cognitive verb functions as space builder. "Please come at once," she hears her mother say, "I found something." Only from Etta's mental space is it possible to represent Etta as hearing what Carla says through the mobile phone. The direct quotes that Etta is hearing are reconstructions too, adding to the fictionalized flavour. Within Carla's directly quoted request to Etta, it is understandable that the unmentionable character of the discovery is referred to as "something."

But Etta knows what this "something" is, as does the reader. "Etta starts to cry." And Etta realizes what the consequences are. "At her mother's home, at first Etta does not want to enter. She is very upset. She does not want to talk about anything, she wants to die." The highly emotional reaction that can be distilled from this stream of free indirect quotes presumably indicates sorrow ("starts to cry"), fear ("does not want to enter; does not want to talk about anything"), and depression ("wants to die"). These emotional states characterize the source as having strong negative feelings about the previous events in terms of loss and remorse; in other words, she is not a cold murderess.

After some time, in paragraph 5 , she acknowledges the facts: "later that day she relates that the baby is hers." A free indirect quote from her embedded space provides the details. "It was born in Beverwijk, in the house where she lived with her boyfriend Jeroen, who was four years older than her." The emotional picture of the mother is elaborated in the subsequent text. In paragraph 6 , it is revealed that she was attached to the corpses: "She would, just like when she still lived there, take the garbage bags out of the bin and fantasized about how things could have been different." She used the corpses to cope with her feelings of loneliness. "After the separation from Jeroen she had decided to take the last baby with her to Haarlem: then she would not feel so lonely." The use of cognitive verbs to construct her embedded space; in this embedded space, free 
indirect thoughts are represented that reveal Etta's motivation. Note that from Etta's space, the dead child is referred to as the "last baby," as if it were alive like the babies of her fantasy.

Paragraph 7 and 8 arrive at the central matter of this news narrative: the explanation of the erratic behaviour. In a long stream of free indirect quotes by Etta, filled with cognitive and modal qualifications that firmly establish her embedded mental space, her motivations are revealed one by one. Why did she not tell anyone that she was pregnant? "She was afraid Jeroen would be angry if he heard she was pregnant." Why did she kill the children? "She never thought she would actually kill the children." Why did she keep the corpses? "She could not part from her lifeless children." And in the very centre of this sequence the actual killing of the children is related in an impersonalized construction: "Yet, that is what happened." Note that this sentence, by its position in the context of free indirect thoughts, bears the suggestion of a free indirect quote: we hear Etta's voice, intertwined with the journalist's voice (Sanders, 2010). By relating the killing in this impersonal, non-cognitive, non-active manner, the actor/news source and the journalist join voices in indicating that she had no intention to kill, and that she did not even experience the killing as an act.

In the last paragraph of the news story (9), the feelings of the babies' father are represented, specifically his regrets towards Etta: "He blames himself for not truly having known Etta." This suggests that if he had acted and felt differently, things would have been different altogether, and thus he is not free of guilt. Again, information represented in an embedded space enforces the picture of the babies' mother as a pitiful, highly troubled woman. Subsequently, the news text reunites, at least for one moment, the babies' mother and father as a couple: they share a cognitive verb which builds a shared embedded mental space. "Etta and Jeroen have decided to have their four babies cremated as soon as this is possible." The closing sentence, represented from the journalist's own narrative content base, finally reunites the dead babies as siblings: "The ashes will be in one urn." Thus the journalist, by way of resolution, adds an element of "normality" to the picture, at least with regards to paying one's last respects.

In presenting this last, normal act by the narrative characters, the journalist points out that normal and erratic behaviour can both be present in one person. This position appeals to the journalist's and audience's level of normality, and implicitly poses the question: What, of this story, is understandable? What can be explained by underlying causes? What would I have done, if some of these circumstances applied to me? Such a presentation, following Alexander (2009), is typical for narrative or literary journalism: "any protracted relationship between a journalist and a subject is likely to bring whatever qualities 
- real or imagined - they may share, to light; this recognition of the familiar in the unfamiliar is a defining characteristic of the frightening which Freud called 'the uncanny."'31 Thus, paradoxically, the narrative journalistic story creates understanding for the culturally remote Other while at the same time disrupting the comfort of both journalist and audience by the engagement with this Other. ${ }^{32}$ Precisely this strangeness, and precisely this fusion of the subjective and objective, explain why "literary" journalistic texts like the one analyzed here are not typically exhausted by one reading: they stay news. ${ }^{33}$

\section{Empirical Research on Perspective Taking}

Constructing the landscape of consciousness invites readers to take the point of view of a certain character. As a result, readers may be better able to understand why someone acted in a certain way, which in turn may lead to a more favourable (or less unfavourable) evaluation of this behaviour as implied by the saying "understanding is forgiving." To our knowledge, no empirical research has addressed the question of whether this effect does occur for newspaper articles such as the ones discussed in this paper. However, there is a line of research on the persuasive impact of stories that appears relevant to this issue.

Green and Brock (2000) showed that reading a story on the murder of a little girl by a psychiatric patient on leave influenced readers' attitudes towards the rights of psychiatric patients, regardless of whether the story was described as factual, fictional, or as a dream. The persuasive potential of stories has been documented in other studies as well. ${ }^{34}$ In models of how stories exert their influence, the feeling of being lost in the story is believed to be the key mechanism. ${ }^{35}$ Green and Brock (2000, Experiment 4) provided evidence for the claim that being enthralled by the narrative was the motor of the narrative's persuasive effect. The feeling of being lost in the story comprises several dimensions, such as the focusing of attention on the story, the feeling of being present at the events, and the extent to which the audience empathizes with the charac-

\footnotetext{
$31 \quad$ Alexander (2009) 61 .

$32 \quad$ Alexander (2009) 62-63.

33 Alexander (2009) 63, quoting Ezra Pound.

34 See, for instance, Appel and Richter (2007); Slater, Rouner, and Long (2006); Strange and Leung (1999).

35 See, for instance, Green and Donahue (2009); Moyer-Gusé (2008); Slater and Rouner (2002).
} 
ters. ${ }^{36}$ These dimensions may not be equally important for a story to have a persuasive effect or, alternatively, the route along which the dimensions influence the persuasive outcome may differ.

Various studies have shown that the extent to which the audience empathizes with characters is an important determinant of the impact a story has on the audience's evaluation. ${ }^{37}$ That is, the more the audience relates to a certain character, the more it is inclined to accept that character's opinions or to evaluate its behaviour favourably. However, these studies are correlational in nature and therefore lend themselves to a rival explanation. Instead of empathizing with a character causing the audience to take on a similar attitude as the character, it could work the other way around: having a similar attitude as the character causes the audience to empathize more strongly with that character. Andsager, Bemker, Choi, and Torwel (2006) provide evidence for such a (reversed) mechanism.

However, De Graaf, Hoeken, Sanders, and Beentjes (2012) were able to manipulate the level of empathy with a character by manipulating the perspective from which the events were related. In two experiments, they studied the persuasive impact of two different stories each of which contained two characters with opposing goals and opinions. For each story, two versions were written which differed with respect to the perspectivising character. That is, the story was either told by the character holding opinion A or by the (opposing) character who held opinion B. If holding a similar opinion drives people to empathise with a character, the audience would identify with a certain character regardless of whether this character was the perspectivising one or not. However, the results showed clearly that participants empathised much more strongly with the perspectivising character, regardless of the opinion held by that character. Furthermore, they were able to demonstrate that this increase in empathy led to a stronger acceptance of the opinions held by the perspectivising character.

The "I"-perspective provides readers with a clear view on the character's landscape of consciousness. The results corroborate the claim that travelling the landscape of consciousness can lead to an understanding and acceptance of the character's opinions and actions. The employment of an "I"-perspective is far more obtrusive than the relatively subtle manipulations of perspective in the newspaper article analysed in the previous section. The techniques

${ }_{3} 6$ See, for instance, Busselle and Bilandzic (2009); De Graaf, Hoeken, Sanders, and Beentjes (2009).

37 See, for instance, De Graaf et al. (2009); Iguarta (2010). 
employed by the journalist lead to the construction of the landscape of consciousness for different persons. To show how the journalist creates these landscapes, we have employed mental space theory. We believe that this theory is highly suitable for our purposes. The concept of an embedded mental space representing what a certain person believed, wanted, and intended is highly similar to the landscape of consciousness concept. In addition, the theory describes the ways in which language elements open up embedded mental spaces, thus establishing narrative shifts such as altered chronology, discovery, complication, and resolution.

A clear identification of these space building language elements is important. For if one wanted to assess whether the construction of embedded spaces leads to the perception of the landscape of consciousness, and subsequently to a better understanding of a person's behaviour, this implies a need for a controlled manipulation of building a mental space. For instance, would the second paragraph have less impact if the events leading to the discovery of the dead infant were not in the present tense, but in the simple past? In other words, not described as happening there and then:

Shortly before Christmas 2005 Carla, who had just become a grandmother to little Esra, was rummaging around in the cellar of her Haarlem residence. She saw a green backpack that she did not know. She thought that it belonged to her eldest daughter, Etta, who recently moved back in with her. (...) When replacing the backpack Carla got the impression that it contained wet clothes. She took out a garbage bag, which contained more garbage bags, towels and moments later she was holding a dead infant, wrapped in a red T-shirt.

And would the identification be less strong if cognitive verbs that build embedded spaces are removed:

Shortly before Christmas 2005 Carla, who had just become a grandmother to little Esra, was rummaging around in the cellar of her Haarlem residence. She replaced a green backpack that belonged to her eldest daughter, Etta, who recently moved back in with her. (...) It was unusually heavy. When Carla unpacked the backpack, a garbage bag appeared, which revealed more garbage bags, towels, and finally a dead infant, wrapped in a red T-shirt. 
Such manipulations enable a precise and controlled assessment of the extent to which the narrative techniques employed by journalists do indeed lead readers to travel the landscape of consciousness in order to understand what made people act the way they did.

The exploration of the inner landscape can be attractive, but it does raise the question whether it has an impact on news papers' perceived quality. Sanders and Redeker (1993) showed that the presentation of free indirect thoughts in news narratives was appreciated by readers, who found such texts more suspenseful than news texts without such elements. However, they did not consider texts with such elements as appropriate news texts. It is an important question when, and in which newspapers the exploration of inner landscapes was introduced and how this development has influenced the public's appreciation; this could well be different for different newspaper styles. We have argued that journalistic background stories function as cultural narratives that move the public back to the dominant cultural order. It is clear, however, that several subcultures can be distinguished within the dominant culture, and more so now with the broadening press landscape and more ubiquitous new media. It can be hypothesized that journalists from different subcultures use narrative techniques in different contexts, depending on their specific cultural order. For instance, in the Dutch broadsheet newspaper that was analyzed in this article (De Volkskrant) as well as in other "quality" press media, the use of sophisticated narrative techniques such as the free indirect style is used to explore seemingly inexplicable behaviour, while tabloid press media might be more inclined to use these techniques to explore the thoughts and emotions of the victims of this erratic behaviour. A larger scaled corpus analysis is needed to compare techniques in these subcultures further.

\section{Concluding Remarks}

The textual analysis presented in this paper shows that journalists employ literary techniques to tell the story. More specifically, we have focused in our analysis on the way in which the journalist overlays his interpretation or even subjective evaluation onto the news facts, and lends his own voice to make the news sources' voices heard. Although the employment of these techniques may provide the reader with an enjoyable reading experience, their impact may go further than simply providing entertainment. By representing the landscape of consciousness of the persons involved, the journalist appears to provide a view on the "intentional state that mitigates or at least makes com- 
prehensible a deviation from a canonical cultural pattern," ${ }^{38}$ which, according to Bruner, is a narrative's goal.

In recent years, crafts as well as morals of narrative journalism have drawn more attention of both professionals (Kramer and Call, 2007) and academics (Sims, 2009) in the journalistic field. Journalistic stories such as this one help to create or maintain a society's understanding of itself and its vulnerabilities, and although journalists do not always think about decisions of technique explicitly as ethical choices in terms of truth or compassion with the subjects, ${ }^{39}$ it is important to recognize the considerable power journalistic choices may have.

\section{References}

Alexander, R., "My story is always escaping into other people': Subjectivity, objectivity, and the double in American literary journalism," in Literary Journalism Studies 1(1) (2009), pp. 57-66.

Andsager, J.L., V. Bemker, H.-L. Choi and V. Torwel, "Perceived similarity of exemplar traits and behavior: Effects on message evaluation," in Communication Research 33(1) (2006), pp. $3^{-18}$.

Appel, M. and T. Richter, "Persuasive effects of fictional narratives increase over time," in Media Psychology 10 (2007), pp. 113-34.

Berkowitz, D. and J.V. TerKeurst, "Community as interpretive community: rethinking the journalist-source relationship," in Journal of Communication 49(3) (1999), pp. $125-36$.

Boyd, B., On the origin of stories. Evolution, cognition, and fiction (Belknap press, 2009). Brown, D.E., Human Universals (McGraw-Hill, 1991).

Bruner, J., Actual minds, possible worlds (Harvard University Press, 1986). , Acts of meaning (Harvard University Press, 1990).

Busselle, R. and H. Bilandzic, "Measuring narrative engagement," in Media Psychology 12(4) (2009), pp. 321-47.

Craig, D., The ethics of the story. Using narrative techniques responsibly in journalism (Rowman and Littlefield, 2006).

Cupchik, G.C. and J. Laszlo, "The landscape of time in literary reception: Character experience and narrative action," in Cognition \& Emotion 8(4) (1994), pp. 297-312.

38 Bruner (1990) 50.

39 Craig (2006) 18-19. 
De Graaf, A., H. Hoeken, J. Sanders and H. Beentjes, “The role of dimensions of narrative engagement in narrative persuasion," in Communications 34(4) (2009), pp. 385-405.

_- "Identification as a mechanism of narrative persuasion," in Communication Research 39 (2012), pp. 802-23.

Dunbar, R.M., Grooming, gossip, and the evolution of language (Harvard University Press, 1996).

__ - "Theory of mind and the evolution of language," in Approaches to the evolution of language, eds.J.R. Hurford, M. Studdert-Kennedy and C. Knight (Cambridge, 1998), pp. 92-110.

—_, "Gossip in evolutionary perspective," General Review of Psychology 8 (2004), pp. 100-10.

Fauconnier, G., Mental Spaces, 2nd ed. (Cambridge, 1985 [1994]).

Fludernik, M., The fictions of language and the languages of fiction: the linguistic representation of speech and consciousness (Routledge, 1993).

Fürsich, E., "In defense of textual analysis. Restoring a challenged method for journalism and media studies," in Journalism Studies 10(2) (2009), pp. 238-52.

Green, M.C. and J. Donahue, "Simulated worlds: Transportation into narratives," in Handbook of imagination and mental simulation, eds. K.D. Markman, W.M.P. Klein and J.A. Suhr (Psychology Press, 2009), pp. 241-56.

Green, M.C. and T.C. Brock, "The role of transportation in the persuasiveness of public narratives," in Journal of Personality and Social Psychology 79(5) (2000), pp. 701-21.

Humphrey, N.K. "The social function of intellect," in Growing points in ethology, eds. P. Bateson and R. Hinde (Cambridge, 1976), pp. 303-17.

Iguarta, J.-J., "Identification with characters and narrative persuasion through fictional feature films," in Communications - the European Journal of Communication Research 35(4) (2010), pp. 347-73.

Kaptein, A., S. van der Geest and F. Meulenberg, "Verhalen verhalen" [Narratives narrate], in Tijdschrift voor Medisch Onderwijs 30(3) (2011), pp. 91-100.

Kramer, M. and W. Call, eds., Telling true stories. A nonfiction writer's guide from the Nieman Foundation at Harvard University (Penguin, 2007).

Marsh, C., "Deeper than the fictional model. Structural origins of literary journalism in Greek mythology and drama," in Journalism Studies 11(2) (2010), pp. 295-310.

Morgan, S., L. Movius and M. Cody, "The power of narratives: the effect of entertainment television organ donation storylines on the attitudes, knowledge, and behaviors of donors and nondonors," in Journal of Communication 59(1) (2009), pp. 135-51.

Moyer-Gusé, E., "Toward a theory of entertainment persuasion: Explaining the persuasive effects of entertainment-education messages," in Communication Theory 18(3) (2008), pp. 407-25. 
Nossek, H. and D. Berkowitz, "Telling 'our' story through the news of terrorism," in Journalism Studies 7(5) (2006), pp. 691-707.

Pinker, S., How the mind works (Penguin, 1997).

Sanders, J., "Intertwined voices. Journalists' representation modes of source information in journalistic subgenres," in English Text Construction 3(2) (2010), pp. 226-49.

Sanders, J. and G. Redeker, "Linguistic perspective in short news stories," in Poetics 22 (1993), pp. 69-87.

-__-, "Perspective and the representation of speech and thought in narrative discourse," in Spaces, worlds and grammar, eds. G. Fauconnier and E. Sweetser(University of Chicago Press, 1996), pp. 290-317.

Sanders, T., J. Sanders and E. Sweetser, "Causality, cognition and communication: A mental space analysis of subjectivity in causal connectives," in Causal Categories in Discourse and Cognition, eds. T. Sanders and E. Sweetser (Mouton de Gruyter, 2009), pp. 21-6o.

__- "Responsible subjects and discourse causality. How mental spaces and connectives help identifying subjectivity in Dutch backward causal connectives," in Journal of Pragmatics 44 (2012), pp. 191-213.

Scalise Sugiyama, M., "On the origins of narrative. Storyteller bias as a fitness-enhancing strategy," in Human Nature 7 (1996), pp. 403-25.

Semino, E. and M. Short, Corpus Stylistics: Speech, Writing and Thought Presentation in a Corpus of English Writing (Routledge, 2004).

Sims, N., "The problem and the promise of literary journalism studies," in Literary Journalism Studies 1(1) (2009), pp. 7-16.

Slater, M.D. and D. Rouner, "Entertainment-education and elaboration likelihood: Understanding the processing of narrative persuasion," in Communication Theory, $12(2)$ (2002), pp. 173-91.

Slater, M.D., D. Rouner and M. Long, "Television dramas and support for controversial public policies: Effects and mechanisms," in Journal of Communication 56(2) (2006), pp. $235^{-52}$.

Strange, J.J. and C.C. Leung, "How anecdotal accounts in news and in fiction can influence judgments of a social problem's urgency, causes, and cures," in Personality and Social Psychology Bulletin, 25(4) (1999), pp. 436-49.

Sweetser, E. and G. Fauconnier, "Cognitive links and domains," in Spaces, worlds and grammar, eds. G. Fauconnier and E. Sweetser (University of Chicago Press, 1996), pp. $1-28$.

Tomasello, M., Origins of human communication (MIT Press, 2008). 
Tomasello, M., M. Carpenter, J. Call, T. Behne and H. Moll, “Understanding and sharing intentions: The origins of cultural cognition," in Behavioral and Brain Sciences 28 (2005), pp. 675-735.

Toolan, M., Narrative. A critical linguistic introduction, 2nd ed. (Routledge, 2001). 